\title{
Libertad condicionada o tres maneras de ser mujer en tiempos de cambio (1920-1940)*
}

\author{
Gabriela Cano \\ Verena Radkau
}

La nueva historiografia dedicada a las mujeres se basa en la tesis de la especificidad de una historia vivida y percibida por las mujeres. En nuestra opinión se trata no tanto de una "historia olvidada", 1 sino de una historia que aún no ha sido escrita.

En la visión androcéntrica presente en la historiografía mexicana, las mujeres aparecen como caso especial y muchas veces marginal de una historia masculina definida como "general". Se las toma en cuenta ocasionalmente cuando invaden espacios de varones y en consecuencia se las analiza con los criterios utilizados para ellos. Sin embargo, en general se las recluye en espacios femeninos "privados" y, como tales, por definición ahistóricos. Aquí está la raíz de la tan evocada "invisibilidad histórica" de las mujeres.

Con los instrumentos usuales de la historiografia (aun de la marxista) en el mejor de los casos se hace visibles a las escasas heroínas que lograron abrirse paso hacia la vida pública y con ello hacia la historicidad. Para encontrar a las demás hay que cambiar los criterios mismos que asignan esta historicidad. Esto implica cambios de puntos de vista, redefiniciones, conceptuaciones heterodoxas.

El rescate de testimonios de mujeres, en los cuales se manifiesten sus experiencias y sus puntos de vista fue el propósito central de nuestra investigación. La construcción de estas fuentes primarias, narraciones de las historias de vida de mujeres de la misma generación y del mismo estrato social se hizo empleando la metodología de historia oral. Las entrevistas intentan recoger las vivencias cotidianas y las percepciones de tres mujeres. El material testimonial recopilado es bastante complejo y extenso. Aquí intentamos apenas una aproximación a su análisis y una sistematización inicial.

Así, interesa destacar que en la conformación de las experiencias narradas en las historias de vida, confluyen tanto el género y la posición social como la generación, además de los innumerables factores individuales constitutivos de la personalidad del sujeto. Desde nuestro punto de vista, la manera en que nuestras entrevistadas viven los procesos de socialización escolar, el trabajo remu-

- Este artículo es la versión sintetizada de un trabajo más amplio que se desarro116 durante 1986-87 en el Programa Interdisciplinario de Estudios de la Mujer (PIEM) de El Colegio de México. En la concepción y en la primera etapa de la investigación participó también Carmen Ramos.

' Así lo supone el subtítulo del recién aparecido libro de Julia Tunón, Mujeres en México. Una historia olvidada, México, Editorial Planeta, 1987. 
nerado, el matrimonio y la maternidad (entre otras experiencias) es resultado de su inserción en circunstancias y momentos históricos particulares. El género, al igual que la situación social y temporal, puede vislumbrarse como alguna de las múltiples coordenadas que cruzan las experiencias humanas $y$, al hacerlo, las van conformando según el momento en que ocurren. No hay que perder de vista que si bien el género, la clase social, y la generación son abstracciones que permiten aislar y clasificar diversos aspectos de la vida humana para el análisis, existen como una unidad. De ahi que pequen de artificialidad aquellos esfuerzos explicativos unicausales (clases o género, por ejemplo) e incluso las interpretaciones dualistas (patriarcado/capitalismo), tan empleadas por estudiosas feministas, que Benería y Roldán han criticado acertadamente en un trabajo reciente. ${ }^{2}$

Las experiencias humanas están entonces inscritas en y son indivisibles de los procesos históricos. Si bien nuestro interés especifico es el análisis de la influencia del género en las historias de vida recopiladas y esta categoria constituye el eje ordenador, tratamos de tener presentes otros factores, como la posición social y la generación. La puntualización de la categoría género por parte de Beneria y Roldán en el estudio mencionado resulta adecuada para los fines del presente trabajo:

El género puede definirse como una red de creencias, rasgos de personalidad, actitudes, sentimientos, valores, comportamientos, y actividades que hacen diferentes a los hombres de las mujeres mediante un proceso de construcción social que tiene una serie de características distintivas. Es un proceso histórico que se desarrolla en diversas esferas macro y micro, como son el Estado, el mercado de trabajo, las escuelas, los medios de comunicación masiva, la legislación, la familia, la unidad doméstica y las relaciones interpersonales. Supone la jerarquización de los rasgos personales y actividades de tal manera que normalmente, se les dé un mayor valor a aquellas acciones y características asociadas a los varones.

Queremos hacer hincapié en la idea de que el género se expresa en una amplia gama de aspectos de la vida humana, tanto en aquellos que tienen que ver con la conciencia, con creencias, sentimientos y valores, como también con actividades de la vida social. La categoría de experiencia, también central en nuestra investigación, nos permite captar esta variedad de manifestaciones de la existencia humana. El historiador inglés E. P. Thompson ha explicado el sentido de emplear la categoría de experiencia para el análisis histórico:

[La experiencia es] una categoria que por imperfecta que pueda ser es indispensable para el historiador ya que incluye la respuesta mental y emocional, ya sea de un individuo o de un grupo social a una pluralidad

2 Lourdes Beneria y Marta Roldán, The Crossroads of Class and Gender. Industrial Homework Subcontracting, and Household Dynamics in Mexico City. Chicago, University of Chicago Press, 1987.

${ }^{3}$ Beneria y Roldán, op. cit., p. 11-12. 
de acontecimientos relacionados entre si o a muchas repeticiones del mismo tipo de acontecimiento. La experiencia surge en el interior del ser social con el pensamiento de hombres y mujeres sobre lo que les ocurre a ellos y a su mundo. El ser social y la conciencia no existen separados más que en la abstracción [...] Dentro del ser social tienen lugar cambios que dan lugar a la experiencia transformada, y esta experiencia es determinante en el sentido en que ejerce presiones sobre la conciencia social existente, plantea nuevas cuestiones y proporciona gran parte del material para ejercicios intelectuales más elaborados. ${ }^{4}$

Esta categoria, capaz de recoger "la respuesta mental y emocional" de los sujetos históricos (individuales o colectivos) resulta entonces indispensable para estudios que empleen testimonios de vida recopilados mediante la metodologia de la historia oral como fuente principal, pues la riqueza de estos relatos es precisamente que expresan el punto de vista de hombres y mujeres sobre la manera de interpretar sus propias acciones, las de los demás y los acontecimientos macrosociales. Otra de las posibilidades para la investigación histórica que nos reporta el empleo de la categoria de la experiencia, es la posibilidad de mostrar las transformaciones de las formas de ser y de actuar de los sujetos. Sólo el seguimiento de estas transformaciones en la experiencia nos permitirá comprender la historia como un proceso.

Luego las categorías de género y de experiencia son instrumentos teóricos que orientan las cualidades, valores, actitudes y creencias, y también el tipo de actividades que comparten tres mujeres de una misma generación y sector social en un determinado momento histórico.

Darles la palabra quizá nos ayude a corregir o matizar la imagen de mujer-víctima que aparece en tantos y bien intencionados intentos de rescate.

Nuestra guia de entrevistas de historia oral sirve de hilo conductor para estructurar los temas abordados y contrastar o comparar a las entrevistadas entre sí. Pero cada una, sin verse encajonada y según las circunstancias de vida personales, enfoca los diversos campos temáticos de manera diferente, privilegiando unos y descartando otros.

Hemos intentado elaborar esta guía teniendo en cuenta las cualidades especificas que desde nuestro punto de vista ha de asumir la historia oral en el caso de las mujeres.

De ahi que demos un espacio amplio a la dimensión supuestamente privada ${ }^{5}$ de la vida de nuestras entrevistadas, sin descuidar sus actividades en el terreno tradicionalmente masculino de la vida "pública" y que tratemos de escudriñar las posibles contradicciones y fricciones entre ambas esferas. El supuesto teórico

\footnotetext{
+ Edward P. Thompson, Miseria de la teoria, Barcelona, Editorial Crítica, Grijalbo, 1981, p. 19-20.

"Añadir el "supuestamente" es pertinente porque cuestionamos la separación entre la esfera privada y una pública que es producto de una determinada ideología de lo femenino.
} 
que sostiene la estructura de la guia es la necesidad de introducir el género como concepto analítico, dándole la misma importancia que tiene un concepto tan aceptado como el de clase. Asi es posible captar a nuestras entrevistadas como miembros de un grupo social distinguible: las mujeres. En otras palabras, no basta entrevistar a mujeres con las preguntas de siempre, ${ }^{6}$ sino que hay que hacerles otras preguntas.

Evidentemente, no todas estas preguntas tendrán respuesta. Pero en estos casos, también los silencios son elocuentes. Observamos en las entrevistas ciertos tabúes, como la sexualidad, donde la información obtenida parece más bien magra. Decimos "parece", porque no hay que olvidar que percepciones y conductas con respecto a determinados fenómenos tanto personales como sociales se manifiestan a menudo de manera indirecta en algún comentario marginal y hasta inesperado. En este sentido hay que aprender a escuchar lo que no se dijo o lo que se dijo en otra forma a la prevista.

Las vidas de nuestras entrevistadas, nacidas a principios del siglo, cubren entre ochenta y noventa años de historia. Sin embargo, al reconstruir sus historias de vida, tanto ellas como nosotras privilegiamos el periodo de su vida comprendido entre los veinte y cuarenta y cinco años de edad. Esta etapa, quizá la más significativa para ellas, corresponde aproximadamente a las décadas veinte y treinta. En estos años de la historia reciente del país ocurrieron importantes transformaciones para la situación social de las mujeres.

El número de mujeres mayores de ochenta años entre las cuales seleccionariamos a nuestras entrevistadas, era de por si reducido, y se restringió más. si se considera que la entrevista en profundidad necesita una base de confianza y que puertas y confianzas, generalmente, no se abren a desconocidos. Requerimos alguna referencia personal para ser admitidas, sobre todo cuando las entrevistas se efectuaron en las casas particulares. En más de un sentido invadimos espacios íntimos.

Finalmente, hicimos entrevistas a tres mujeres, nacidas entre 1898 y 1911. Alura Flores ha sido maestra de educación física, declamadora profesional y promotora de bailes y atuendos folclóricos; Josefina Vicens, además de ser autora de dos novelas sobresalientes, ha sido funcionaria de organizaciones campesinas hegemónicas, cronista de toros, dirigente de trabajadores cinematográficos y escritora de guiones de cine; Guadalupe Zúñiga, psicóloga, fue juez del Tribunal para Menores y profesora universitaria en las áreas de psicología y trabajo social. Las trayectorias personales de estas tres mujeres han seguido cursos diversos, tanto en el ámbito público como en el privado. En sus testimonios puede apreciarse una muestra de la variedad de sus experiencias, percepciones y opiniones; incluso es posible vislumbrar en los relatos aspectos de los temperamentos de las entrevistadas. La riqueza de los testimonios, manifestación de individualidades, re-

' Las pocas entrevistas a mujeres existentes, por ejemplo, en el Archivo de la Palabra del Instituto Mora no dicen mucho sobre su experiencia como seres hùmanos femeninos. 
basa el análisis del presente artículo y sólo podrá apreciarse en los testimonios mismos.

Por encima de la diversidad, las tres comparten la generación, el origen de clase, el espacio urbano de la ciudad de México y el ejercicio de una profesión cuando todavía no era común entre las mujeres de su estrato social. Este último dato nos indica que Guadalupe Zúniga de González, Alura Flores y Josefina Vicens no son precisamente mujeres "comunes y corrientes". A su manera, cada una se desvió de las normas vigentes. Ejercian lo que el historiador italiano Carlo Ginzburg llama "la propia libertad condicionada" dentro de "una jaula flexible e invisible."7

Pero cómo y hasta dónde lo hacian nos dice mucho sobre estas normas y condiciones vigentes. En la inconformidad (tanto implicita como explicita) que con diferentes matices muestran las tres, surge quizá con mayor claridad el significado de ser mujer en la primera mitad del siglo $\mathrm{x} \times$ mexicano. Cuando un proyecto de vida personal transgrede lo socialmente establecido, en nuestro caso la feminidad, es precisamente esta transgresión la que define los límites impuestos. Este es un aspecto más de lo que hemos llamado el proceso de desentrañar la compleja relación entre el proceso social y la vida individual.

Optamos por estructurar el análisis de las entrevistadas por temas, siguiendo el orden cronológico que sugiere la guia. Las tres entrevistadas recuerdan un régimen familiar de bastante disciplina, misma que podia ser ejercida sobre todo por el padre (de formación militar en el caso de $\mathbf{G}$. Zúñiga), la madre (norteamericana de religión protestante bautista en el caso de A. Flores) o ambos padres (el caso de Josefina Vicens).

"Fue una disciplina muy seria; pero yo creo que en mi caso personal fue más dura por la formación de mi papá en el colegio militar."8

"Mi madre fue una persona que nos tenía realmente con una gran disciplina..."

"Para mi mamá me portaba yo muy mal. Cuando gané el concurso de balero de toda la cuadra [...] me dijo mi papá: 'Tú acabarás en la cárcel.' $Y$ ese estribillo lo oí muchísimo tiempo en mi casa." 10

La única a la que no molestaba esta disciplina, es Alura Flores, quizá por el origen religioso de las normas que regulan su vida.

A mi nunca me pesó la disciplina de mi madre, ni de mi padre, nunca, al contrario..."

Pero tanto G. Zúñiga, como Vicens reconocen que en más de una ocasión el deber ser chocaba con su ser. Quizá por ello recuerdan con especial cariño su paso por la escuela primaria que con

\footnotetext{
Carlo Ginzburg, El queso y los gusanos. El cosmos seguin un molinero del siglo XVI, Barcelona, Muchnick Editores, 1981, p. 22.

" Entrevista con G. Zúniga, p. 4.

${ }^{-}$Entrevista con A. Flores, p. 3.

16) Entrevista con J. Vicens, p. 4.

"Flores, p. 6.
} 
todo y sus limitaciones era un espacio para satisfacer curiosidades y cometer "maldades" y "travesuras".

De mi primera infancia sólo recuerdo las maldades que hacia yo en la escuela primaria junto con mis amigas, éramos muy fiesteras, a pesar del cuidado que tenian con nosotras las maestras. ${ }^{12}$

Yo era feliz en la escuela; me gustaba todo [...] Había más niñas que niños en la escuela. Los maestros eran un poco más enérgicos con los varones. Porque ellos además eran más bárbaros... 13

Me portaba mal en la escuela, siempre me he portado mal, esa es la verdad, bueno, según calculen qué es mal o bien. ${ }^{14}$

Los lugares de juego eran los patios de la escuela y de la casa y aun las calles donde habia posibilidades de juntarse con los niños del vecindario.

Jugábamos al pan y queso [...] Era un juego muy común y corriente. La famosa Doña Blanca: "Doña Blanca está cubierta de pilares de oro y plata." Esos eran los juegos de entonces. También a San Miguelito; éste también es un juego muy viejo. Después de la escuela no jugábamos así, pues es que después de la escuela nada más cada quien con su familia. ${ }^{15}$

[La casa] tenía un patio enorme también, muy grande, en donde jugábamos a la riata y a la pelota con los niños de las otras viviendas. Cuando habia piñatas, ahi las haciamos. ${ }^{16}$

[...] me gustaba jugar a las coleadas, a agarrarse de los coches así en patines y luego sentir la coleada. Para lo que era yo una nulidad era para el trompo. Jamás logré bailar un trompo. En cambio para el balero era yo sensacional. Y me gustaban las escondidas, la matatena y el hoyito matón [...] también jugaba yo a las canicas. Jugaba con los chamacos de la cuadra; algunos de ellos no iban a la misma escuela que yo porque eran riquillos, entonces los mandaban a una escuela particular, pero vivían en la cuadra en unas casas mejores. Eramos cuates de la cuadra. ${ }^{17}$

Las tres fueron buenas y aplicadas alumnas, por interés propio y por presiones paternales. La educación formal iba a jugar un papel importante en la realización vital de Guadalupe Zúniga y Alura Flores, mientras Josefina Vicens, siempre la más rebelde, optó por la heterodoxa vía autodidacta.

En realidad, yo creo que la disciplina de mi papá influyó. Siempre tuve premio, siempre tuve mi diploma de primer premio.

[...] lo digo sin ninguna pretensión, era yo muy buena alumna. Me sacaba rete buenas calificaciones. ${ }^{19}$

Los relatos indican que la infancia, aun para las niñas, era una época de tolerancia donde el género, a pesar de estar presente, se subordinaba en ocasiones a la edad.

12 Zúniga, p. 1.

13 Vicens, p. 3.

14 Ibid. p. 4.

15 Zúniga, p. 4.

16 Flores, p. 7.

17 Vicens, p. 4.

it Zúniga, p. 2.

14 Vicens, p. 3. 
Con la entrada a la adolescencia cambiaron las cosas.

En época de Guadalupe Zúniga y Alura Flores, en la segunda década del siglo $\mathrm{XX}$, no existía aún secundaria, sino que se pasaba directamente a la Escuela Normal para Señoritas (el caso de la señora Zúñiga) o (el de Alura Flores) a la Nacional Preparatoria. ${ }^{20}$ Las opciones de educación formal superior eran aún limitadas para las señoritas de clase media. Recordemos que apenas unas décadas antes, durante la paz porfiriana, se habian abierto de manera significativa las aulas a las mujeres. El magisterio atraía a la mayoria de ellas ya que por su compatibilidad con lo que se consideraba propio para la condición femenina, era socialmente aceptable. Las más audaces se lanzaban a carreras como la medicina, la odontologia o la abc gacía.

Veremos que entrado el siglo $\mathrm{xx}$ el panorama no había cambiado tanto.

En la Normal estuve tres años. Entré sumamente joven, al salir de la primaria [...] la mejor escuela profesional para niñas era la Normal. Así es que de sexto año de primaria, a la Escuela Normal y la que tenía ganas de seguir estudiando, a Filosofía y Letras para continuar su preparación, pero no habia otras escuelas. ${ }^{21}$

Es interesante notar que ya en la época de la adolescencia de nuestras entrevistadas la carrera de maestra, como única opción de movilidad social para las mujeres, al parecer habia perdido prestigio. A pesar de los elogios que tienen para la Normal, la Escuela de Altos Estudios está situada claramente en un nivel superior. $^{22}$

Claro que las mujeres, que las hubo por fortuna superiores, no se conformaban o no tenian vocación para maestras y estudiaban alguna otra profesión, ya fuera medicina -que era generalmente la que tomabano de abogados, pero no había muchas. ${ }^{23}$

Esto puede indicar que, al menos en el nivel de las aspiraciones, el horizonte profesional para el género femenino se habia ensanchado.

En términos generales, para estas mujeres la educación superior y profesional era todavía una conquista reciente. En su memoria, esta etapa de formación se convierte en fundamental para su vida posterior $y$, por lo menos desde la retrospectiva, se juzga como excepcional y privilegiada. El contenido del conocimiento enciclo-

20 La Escuela Normal para Señoritas se fundó en 1889. Era una opción terminal que daba título de maestra. La Escuela Nacional Preparatoria era aquella famosa fundada por el padre del positivismo mexicano, Gabino Barreda, unas decadas antes. Después de haber cursado aproximadamente 3 años de la Normal o de la Preparatoria, existia la posibilidad de seguir, ya a nivel universitario, en la Escuela de Altos Estudios (1910) que se convirtió en 1921 en la Facultad de Filosofia y Letras de la UNM. La secundaria se inicia en 1924.

21 Zúniga, p. 7.

2 Hay un testimonio recopilado en Prieto et al., 1987, 389 y ss., que corrobora esta impresión. Se trata de dona Felisa Argüelles, esposa de Jorge Prieto, nacida en 1900: “... se hacia una buena carrera en la Normal... mi hermana sí pasó a Altos Estudios, lo que después fue Filosofia y Letras; ella sí se habia nutrido... en la cultura de mi papá..."

23 Zúniga, p. 8. 
pédico propio de la época no solamente no se cuestiona, sino que se considera superior, en el sentido de más completo, frente a la actual educación. Los maestros son recordados no sólo con respeto, sino con verdadera veneración.

el gobierno le dio mucho impulso a la Escuela Normal donde realmente hubo lumbreras: Ezequiel Chávez, Enrique Aragón. ${ }^{24}$

¡Qué maestros, qué sabiduría, qué exactitud! ${ }^{25}$

Al que más recuerdo de forma palpitante es Erasmo Castellanos y que nunca olvidaré, porque inclusive aún ya salida, siendo egresada de la preparatoria, íbamos a escuchar sus clases. Daba clases de literatura universal [...] De matemáticas recuerdo a Nápoles Gándara [...] y Ochoterena en biologia. ${ }^{26}$

Lejos quedaban aún los problemas de la universidad de masas. Los grupos de estudiantes eran pequeños y a las pocas mujeres se las podia contar con los dedos de una mano. ${ }^{27}$ En estas circunstancias era fácil desarrollar un espíritu de cuerpo como Alura Flores a quien además le tocaron condiscipulos que posteriormente se volverían personalidades históricas: Miguel Alemán, Salvador Novo, Javier Villaurrutia, José Muñóz Cota. Todos ellos pertenecientes a la generación preparatoriana de 1920-24, de la cual la señora Flores se siente "realmente muy orgullosa".28

Sin embargo, en esta fase de formación calificada como "feliz" por las dos entrevistadas que la vivieron, se abrieron cada vez más las fisuras entre el ser y el deber ser (femeninos) que hemos mencionado. En una actitud bastante ambigua, tanto la familia como la sociedad en su conjunto, por una parte impulsaron la superación individual de las jóvenes en términos generales, para, al mismo tiempo, obstaculizarla o al menos limitarla en su realización concreta. Guadalupe Zúniga recuerda:

Las penas que yo sufri cuando [...] llegaba de la universidad [...] En la Escuela de Altos Estudios salíamos a las nueve de la noche, o a veces a las ocho. Pero para llegar a donde yo vivía estaba largo, por eso llegaba yo tarde y estaba ahi la molestia, el problema, la protesta del papá militar. Además yo tenia que salir de mis estudios con alguno de mis hermanos, yo sola no. Ellos estaban estudiando y era su obligación que yo viniera con ellos. Si llegaba sola, ahí estaba el disgusto. Mi papá se puso muy duro, porque le dije: "Pues, yo tengo que seguir estudiando." -"Pues no vas a llegar aguí sin tus hermanos. Si no te conviene vivir aquí, pues no vivas aquí." -"Pues, no vivo."29

Alura Flores refiere, sin desagrado, incluso una separación espacial entre varones y mujeres.

24 Ibid. La señora Felicia Argüelles de Prieto comparte esa admiración: "habia verdaderos talentos como Palma Guillén, Margarita Quijano [...] Ezequiel Chávez [...]iQué diferente era la educación entonces!, qué completa [...]" (Prieto et al., 1987:390).

is Zúniga, p. 6.

26. Flores, p. 9.

27 "fue tan preciosa esa época porque éramos muy pocos alumnos". (Zúniga, p.

5) "Eramos pocas. En el salón de clase donde había treinta hombres, habíamos unas cuatro, cinco, seis mujeres." (Flores, p. 16.)

${ }^{28} \mathrm{Ibid}$.

29 Zúniga, p. 5. 
Las mujeres estábamos dentro del recinto de lo que es propiamente San Ildefonso. En el tercer piso teniamos un área que le llamaban el Gineceo [...] teníamos salas de estudio especialmente para nosotras y teníamos una prefecta que se llamó Dolores Castillos [...] y que estaba muy pendiente y muy celosa de las muchachas: que no se juntaran mucho con los muchachos. ${ }^{30}$

Nos custodiaba como si fuéramos realmente unas santas; era un cuidado especial en aquellas épocas, no como ahora que se han roto todos los tabues, ahora ya no existe nada de eso. ${ }^{31}$

Pero hay indicios de que incluso bajo esta vigilancia estricta era posible para las muchachas echar novio y juntarse en palomillas. ${ }^{32}$

Las fricciones en lo doméstico variaban según los casos particulares. Mientras Guadalupe Zúñiga las recuerda como bastante fuertes, ${ }^{33}$ en la familia de Alura Flores al parecer eran menos marcadas, lo que ella misma atribuye a la nacionalidad estadunidense de su madre.

mi madre siendo norteamericana, no era tan cerrada como algunas madres mexicanas. ${ }^{34}$

Aparte de las peculiaridades de la existencia femenina relacionadas directamente con la formación académica, nuestras entrevistadas refieren otros de sus aspectos en este periodo de su vida.

Ir a bailes o similares diversiones nocturnas estaba naturalmente condicionado a la presencia de un chaperón o una chaperona.

Diversiones teníamos con muchos trabajos, uno que otro baile, rarisima vez. Eso fue mucho más adelante, siempre que fuera la mamá con nosotras. Vamos, que una señorita fuera sin la mamá, imposible. Y si, por estarnos polveando o arreglando, nos daban las diez, ya no saliamos. ${ }^{35}$

Los varones podian ir solos y tenian además el privilegio de elegir.

Los muchachos, también sinvergüenzas, estaban echando ojo a ver cuál les convenia más. Les haciamos el favor de aceptar con mucho gusto. ${ }^{36}$

Cuando salía con los novios llevaba chaperonas, desde luego. Si estamos hablando de la prehistoria [...] Si estaban ahí los novios, mi papá - mi mamá estaban ahí sentados en la sala, no podíamos ni platicar nada. Siempre salíamos con alguna de mis hermanas o de las del novio [...] Entonces era una vigilancia tremenda. ${ }^{37}$

3" Flores, p. 14.

31 Flores, p. 15.

32 Al menos para las notables, como Frida Kahlo o Ernestina Marín, su amiga intima, quienes pertenecian a la palomilla de "Los Cachuchas". El novio de Frida fue Alejandro Gómez Arias, hasta que fue desplazado por Diego Rivera, quien llegó para pintar su mural en el anfiteatro Bolívar. (Flores, p. 14.)

${ }_{33}$ La madre es recordada como más permisiva: "siempre la mamá ha sido muchísimo más comprensiva". (Zúñiga, p. 12-13.)

${ }^{34}$ Flores, p. 15.

${ }^{3 s}$ Zúñiga, p. 12.

Ito Ibid.

"Vicens, p. 18. 
Para relacionarse de manera un poco menos controlada habia que darse "escapadas". De su primer novio, a quien conoció cuando ella ya daba clases, cuenta Guadalupe Zúñiga:

Se llamaba Rubén [...] Nos veíamos en la escuela, allí en la Alameda de Santa María que estaba cerca de nuestra escuela; ahí platicábamos, poquito tiempo; tenia uno que llegar a su casa a determinada hora. Nos dábamos nuestras escapadas. ${ }^{38}$

Al parecer, los jóvenes en las primeras décadas de nuestro siglo, mostraban una buena porción de conformidad con las prescripciones sociales y en ocasiones rebasaban en conservadurismo a los adultos. El siguiente episodio da cuenta de ello.

Cuando se empezó a usar el pelo corto, hasta se pelearon los de la Escuela de Medicina con los de la Normal (estaban cercanas una a la otra). Eso de que nos hubiéramos cortado el pelo en aquel tiempo produjo un escalofrío moral a los muchachos. No lo toleraban. Muchacha con pelo cortado que pasaba por la Escuela de Medicina -entonces en Santo Domingo- se la metían los muchachos para castigarla. ${ }^{39}$

La moral victoriana cuyo peso sofocante recaía especialmente sobre las mujeres, pretendía conservarse incluso en situaciones donde la realidad la revelaba como algo ya obsoleto. Alura Flores, quien desde la preparatoria se dedicaba a los deportes, actividad de por sí poco ortodoxa para una mujer, tuvo que sufrir esta incongruencia en carne propia.

Las mujeres sí podian nadar, pero se consideraba un poquito deshonesto, mostrar [...] eran unos trajes no como los de ahora, tenian una faldita pequeña y eran todos cubiertos, simplemente se veían los brazos y del muslo al pie, pero de todas maneras [...] Los uniformes de deportes eran una especie de pantalones con mucho pliegue que nos llegaban abajo de la rodilla, posteriormente los usábamos arriba de la rodilla, porque nos era menos estorboso, nos daba un poquito más de libertad de movimiento. ${ }^{40}$

Las mujeres que querían este "poquito más de movimiento" y ambicionaban espacios más amplios que los tradicionalmente asignados, tenían que enfrentarse a un mundo hecho por y para seres humanos masculinos. Ello implicaba también someterse a valores que no formaban parte de los cánones de la educación femenina: competitividad, agresividad, extroversión, etc. Nuestras entrevistadas tienen plena conciencia de esta situación y se entienden como pioneras:

Fuimos de las primeras mujeres que incursionamos en la vida del hombre propiamente dentro de la Escuela Nacional Preparatoria. ${ }^{41}$

38 Zúniga, p. 13.

39 Ibid.

40 Flores, p. 15. Más tarde, cuando ya trabajaba como maestra de deportes, Alura Flores iba a pugnar por la implantación del short también para las mujeres, iniciando, como ella misma dice, "la era moderna".

41 Flores, p. 16. 
La adolescencia de Josefina Vicens difiere de la de las otras dos entrevistadas porque fue determinada por un doble desafio: el rechazo a las pautas tradicionales que seguia el destino femenino, pero también a los nuevos caminos que tortuosamente, trazados dentro de un marco todavia bastante tradicional, se abrian a las mujeres de su clase.

Como yo lo que queria era libertad y trabajar, entonces, acabando la primaria, me metí a estudiar una carrera de comercio que era de dos años [...] pero yo la hice en uno y después, al poquito tiempo, empecé a trabajar. ${ }^{42}$

Aqui, como en el caso de la actividad deportiva de Alura Flores, hubo respaldo familiar. ${ }^{43} \mathrm{El}$ tránsito hacia una vida adulta fue aparentemente sin rupturas. Josefina seguia viviendo en la casa de sus papás a quienes, en calidad de hija dependiente, entregaba su escaso salario, y, además de trabajar como mecanógrafa, hacia las cosas propias de su edad cronológica: jugaba con los dos hijos de su patrón ${ }^{44}$ y con los muchachos de su cuadra. ${ }^{45}$

Josefina Vicens, así como G. Zúñiga y Alura Flores, está consciente de su condición excepcional:

Era yo la única de mis hermanas que trabajaba. Mi hermana mayor estudiaba en el Conservatorio. Después yo, que soy [...] que hice un lío [...] Después mi hermana calificada por Josefina como "muy recatapeinetitas. [Una hermana calificada por Josefina como "muy recatadita, muy feminita."] Luego mi hermana Chabela que sí estudió secundaria y mi hermana Gloria también. Las últimas hermanas fueron las que estudiaron. ${ }^{46}$

Las tres entrevistadas contrajeron matrimonio. Alura Flores conoció a su futuro esposo ya en la prepartoria:

Otro recuerdo de la preparatoria -pues que conoci al padre de mi hijo, se llamó Alfonso Canales, de ahí pasó a medicina [..] Lo conocí dentro del deporte [...] Los dos entramos a la Escuela de Educación Física. ${ }^{47}$ Entonces fue cuando nos casamos, porque ya podíamos tener un poquito de entradas, creímos que la vida era fácil, más no fue así. No fue así porque desgraciadamente murió muy prematuramente. ${ }^{48}$

También el marido de Guadalupe Zúñiga era médico:

Yo me casé con un médico y él tenía que ver alguna cosa con esos problemas, ${ }^{49}$ yo creo que por eso nos conocimos. No tengo en este

42 Vicens, p. 13.

${ }^{43}$ Ibid.

t4 Vicens, p. 14.

t5 Vicens, p. 16.

th Una de las razones para esta inclinación al estudio pudo haber sido que -como ya se dijo- a partir de 1924 existia la secundaria.

17 Esta escuela fue impulsada por José Vasconcelos, pero duró sólo una generación de tres años. Después fue sustituida por la Escuela de Educación Física Universitaria.

${ }_{48}^{4}$ Flores, p. 17. Ya madura, Alura Flores se casó por segunda vez. Este matrimonio duró 37 años.

${ }^{+4}$ Se refiere a su trabajo con menores infractores, del cual hablaremos más adelante. 
momento el motivo principal, pero era estudiante de medicina [...] Creo que me casé en 26 , muchos años hace $[. . .]^{50}$

El compañero de Josefina Vicens era amigo de un novio de ella. El novio murió ahogado en el mar veracruzano, accidente que terminó bruscamente con el sueño de "correr mundo" de ambos jóvenes. Por cierto, ella lo había envidiado mucho por la posibilidad varonil de vagabundear. Después el amigo sobreviviente se convirtió en marido, tras la repentina pregunta a Josefina de "¿Oye. no te quieres casar conmigo?" Y decidieron casarse.

En la retrospectiva, para ninguna de las tres mujeres el matrimonio parece significar un paso de gran trascendencia en su vida. Como que sucedió y ya. Es notable la ausencia de los esposos en las narraciones. El factor tiempo no parece indicado para explicar el fenómeno, ya que éste se da tanto en los matrimonios de corta duración (Flores, Vicens), como en la unión más larga (Zúñiga). Parece que en la vida posterior al casamiento sucedieron cosas que para nuestras entrevistadas cobraron un peso mayor y opacaron un tanto el recuerdo de la pareja. Donde más presente está, es en la memoria de Josefina Vicens, pero precisamente no en calidad de marido, sino del amigo que fue tanto antes como después de la corta relación matrimonial.

En suma, para la periodización personal, el matrimonio, al parecer, fue mucho menos impresionante que por ejemplo los avances de la vida profesional. Se recuerda más bien como algo que no estorbaba otras actividades más significativas.

Sólo Josefina Vicens cuestiona la institución como tal, al menos para su realización vital.

Yo en realidad no me hubiera casado, no era una cosa que me llamara mucho la atención. El sí me llamaba la atención, pero no el matrimonio. ${ }^{52}$

Sin embargo, también ella, la menos conformista de las tres, se sometió a ciertas presiones sociales:

yo pensé esto: "Bueno, yo me largo de la casa con él y mi papá, creo que lo busca y le da de balazos; mi mamá se cae desmayada del disgusto." Además, tengo tres hermanas menores; no tengo derecho tampoco a que entonces cualquier fulano las enamore y les diga, "ah, pues si ya tu hermana se fue sin casarse". ${ }^{53}$

Pero la responsabilidad familiar terminó ahí. Ya para su separación después de un año, Josefina Vicens aplicó sus propios criterios ante las protestas de su madre:

Momentito, señora, ahora sí ya nada; yo sali de mi casa casada por la Iglesia y por lo civil. Ahora es mi vida y si me quiero separar a los tres días, me separo a los tres días. ${ }^{54}$

5) Zúniga, p. 20.

5 Vicens, p. 17.

s? Vicens, p. 22.

53 Ibid.

it Ibid. 
Aqui queda claro que el vínculo matrimonial en ocasiones sirve para cortar otro vínculo, el familiar.

La libertad que podía anhelar una joven en el matrimonio era desde luego muy relativa:

La obligación de llegar a la casa y todo eso, como que no nos gustaba, ni a él ni a mi. 55

Para Josefina Vicens, la verdadera independencia empezó después del matrimonio, cuando vivia sola.

Guadalupe Zúñiga y Alura Flores seguian su camino en esta combinación entre lo convencional y lo novedoso que ya hemos mencionado. Se casaron, tuvieron cada una un hijo, como para cumplir también con esa función femenina, y por lo demás no permitian que su vida profesional se trastocara. Las entrevistadas hacen hincapié en que nunca dejaron de trabajar.

Tanto Guadalupe Zúniga como Alura Flores permanecian dentro de estructuras familiares aparentemente tradicionales: aun después de casadas vivian en la casa de los padres. Sin embargo, ellas aprovechaban la infraestructura doméstico-familiar del ámbito "privado" para posibilitar su incursión en la vida "pública" del trabajo. En ambos casos fue la madre quien en calidad de vicaria de la hija se encargaba sobre todo de la crianza del nieto. Las hijas saben lo que les deben:

Mi mamá me resolvia todos los problemas; si no ha sido por mi mamá, no hubiera podido hacer todo. ${ }^{56}$

Tuve la dicha de tener una madrecita muy preciosa [...] Yo le dejaba mi niño a mi madre y me iba a trabajar. ${ }^{57}$

En los recuerdos de ambas, esta fase de su vida no presentaba problema alguno en cuanto a la familia, o, como se expresa $\mathbf{G}$. Zúniga: "La casa marchaba como en rieles." sanos, aplicados en la escuela y, más adelante se convirtieron en profesionales de éxito. Pero no hay que olvidar que sus madres estaban durante largas horas lejos del hogar y sus problemas cotidianos. Quizá los recuerdos de las abuelas que tuvieron que batallar con el servicio doméstico y los achaques de la infancia -si pudiéramos evocarlos-, pintarian un cuadro menos idílico.

Tanto Guadalupe Zúñiga como Josefina Vicens se declaran explícitamente incompetentes para los quehaceres domésticos:

Yo no sé nada de eso. Bueno, cuando me quedo sola, muchas veces no hay remedio, tengo que hacer, pero no es frecuente. ${ }^{59}$

Yo he sido la menos hogareña del mundo [...] no sé hacer un solo guiso, nada. Si yo no tuviera quien me cocinara y no tuviera yo algo de dinero para un restaurant, pues yo me moriría de hambre. ${ }^{60}$

ss Ibid.

${ }^{56}$ Zúniga, p. 20.

57 Flores, p. 17.

s* Zúniga, p. 20.

59 Zúñiga, p. 22.

bil Vicens, p. 38. 
Parece que esta incompetencia surgió por decisión propia, ya que al menos Josefina Vicens refiere los esfuerzos de su madre por entrenarla en las labores "propias de su sexo".61

Entre lo que hacian nuestras entrevistadas en concreto con su maternidad y lo que pensaban más o menos explícitamente de ella en términos generales, no siempre había concordancia.

Así afirma Alura Flores:

pienso que para una madre lo más grande es su hijo, es decir la maternidad es la que nos da el mayor valor, pienso yo, a las mujeres. ${ }^{62}$

En las dos novelas, El libro vacio y Los años falsos que llevaron a Josefina Vicens a ser reconocida como escritora, los protagonistas son hombres; los personajes femeninos no tienen nombre y cumplen su destino genérico de manera bastante tradicional. Para la autora no es extraño, para ella esas mujeres tradicionales tienen virtudes que incluso las colocan por encima de los varones.

Una mujer es mucho más sabia para llevar hijos que un hombre porque ella tiene un instinto [...] A mí como la maternidad me parece maravillosa, absolutamente maravillosa, un milagro sensacional, entonces la mujer como que nunca se desprende totalmente de ésta y como que está más interiorizada con los hijos que el padre. Claro, no en todos los casos, pero creo que así es en general. ${ }^{63}$

La maternidad abstracta es entonces reconocida tal como lo exigía la ideología dominante de la feminidad, mientras que la maternidad concreta, sobre todo en sus esclavizantes aspectos de carga doméstica, se relega a un segundo plano. ${ }^{64}$

Josefina Vicens es la más tajante:

Todas mis hermanas fueron amas de casa, y todas tuvieron hijos, menos yo [...] Yo pensé en tener hijos, pero con mucho miedo, porque decía yo: sería bonito, pero [...] Lo pensaba yo tanto que quiere decir que no tenía yo ganas. Porque no era el instinto así femenino de, ay, ay, yo un hijo. Yo decía: ay, Dios mío, cuando veía yo a mis sobrinillos que se enfermaban y que mis hermanas sufrían [...] demasiado sufro ya con mis sobrinos para traer hijos, pensaba yo [...] no hice nada por evitarlos, pero decir así que estoy frustrada, porque no tuve un hijo, les diría puras mentiras, y yo no soy de esa gente. ${ }^{65}$

En ese "no soy de esa gente" reforzado con la autocalificación de "como que nada femenina" se expresa nuevamente la conciencia de lo excepcional de la propia vida, la necesidad de un deslinde, sin desprestigiar a los demás.

Además, la ruptura con los papeles y valores femeninos tradicionales tampoco en este caso es tan drástica como aparenta:

"I Ibid.

62 Fiores, p. 24.

n.3 Vicens, p. 5.

${ }^{\text {it }}$ En ocasiones simplemente no hubo tiempo: "¿Cómo no habria de querer tener más hijos? Pero creo que no tuve tiempo. Nada de que yo dije: ya no voy a tener más hijos, pero yo creo que falto tiempo." (Zúniga, p. 21.) "Ha sido demasiado agitada [...] mi vida -el trabajo, los amigos, el matrimonio mismo, todo esocomo para dedicarme o solazarme en cosas del hogar." (Vicens, p. 39).

${ }^{65}$ Vicens, p. 40. 
Con mis sobrinos, tenía una relación como de mamá. Problema que tenían serio, mis sobrinos iban conmigo, no iban con sus mamás [...] Yo tenía pláticas con ellos y todavía tienen cualquier problema, así muy grande, y vienen conmigo. Soy madrina de uno, pero todos me dicen madrina Peque, madrina Peque, todos. ${ }^{66}$

Lo que en los tres casos ocupa el espacio más amplio en los recuerdos y suscita los detalles más vivos, es, indudablemente, la vida del trabajo.

Guadalupe Zúñiga, después de terminar la carrera de psicologia en la Escuela de Altos Estudios, se convirtió en "la primera juez mexicana" en el Tribunal de Menores, fundado en diciembre de 1926, nombramiento que, insiste, no le causó miedo, pero sí sorpresa:

siempre habían sido hombres los jueces, resulté yo la primera mujer. ${ }^{67}$

A ella le tocaban, "desde luego", los casos de las jóvenes infractoras, pero en colaboración con los demás integrantes masculinos del tribunal, un médico y un maestro. A pesar de que, en forma somera, asegura que no había conflictos de fondo en esta colaboración intergéneros, éstos, ya entrando en detalles, salen a flote.

Hubo casos bastante difíciles porque como éramos tres jueces no siempre coincidíamos en el camino que había que seguir [...] en los casos de mujeres sí habia diferencias de criterio muy profundas. Yo era muy optimista y los dos jueces hombres, como hombres, eran menos sensitivos. Siempre la psicología femenina tiene otras luces. Vemos las cosas de otro modo [...] Las mujeres como vemos las cosas con más naturalidad, sin prejuicios, con más sensibilidad y habiendo sensibilidad en el juicio, pues claro que se atenúa o se matiza hasta donde sea posible. En cambio, los hombres son más duros, más drásticos, con menos visión de la realidad que la que las mujeres tenemos. ${ }^{68}$

La organización de los jueces aparentemente no era jerárquica. Pero el trabajo cotidiano mostraba otros matices.

Uno era el presidente y, claro, el hombre tenía que ser el presidente. Pues eran hombres, se aprovechaban. ${ }^{69}$

Podemos estar de acuerdo o no con las opiniones de la señora Zúniga acerca de lo masculino y lo femenino, pero es evidente que tiene lo que podriamos llamar autopercepción de género, que se movia en el mundo masculino consciente de su otredad.

A la juez le correspondía evaluar los "desórdenes de conducta" -robo, faltas de orden sexual, insubordinación en el hogar-. ${ }^{70}$

En su juicio posterior sobre estos desórdenes se observa de

so Ibid.

67 Zúñiga, p. 14.

n* Zúniga, p. 15. A un juicio muy similar llega Josefina Vicens al comentar los personajes femeninos de sus libros: "En fin, todo eso instintivo de la mujer hace que esté más apegada a la vida real..." (Vicens, p. 6.)

hy Ibid.

${ }^{70}$ Zúniga, p. 16. 
nuevo una aceptación de los valores sociales en general, al mismo tiempo que su no aplicación en muchos ámbitos de la vida individual. La familia tradicional es el ideal, al cual.su propia familia no correspondía del todo. Las condiciones indispensables para la realización de la mujer son su calidad de casada y de madre. Aunque formalmente ella había cumplido con estos requisitos básicos, hemos visto que su realización como ser humano femenino no se dio en los espacios domésticos.

Para Alura Flores, los enfrentamientos con sus colegas varones eran más marcados y los recuerda aún con cierta amargura:

esa fue una de las causas por las que me jubile.."

En parte, se debe a que como entrenadora y maestra de deportes (sobre todo básket y voleibol) había escogido un campo de actividad competitivo y masculino por excelencia, donde además no sólo se trataba de destacar intelectual, sino también físicamente.

Una de las cosas más desagradable que sentia, era el encono de los hombres cuando un entrenador mujer les ganaba. ¿Cómo va a ser posible que un entrenador mujer les ganara en los deportes a los hombres que se creían únicos? $?^{2}$

Ante este "celo" de parte de los varones, los éxitos logrados con sus alumnas significan todavía en el recuerdo un triunfo como entrenadora y como mujer:

fui muy feliz, porque la satisfacción más grande que yo tenía era ver que mis muchachitas, que inclusive no eran muy hermosas ni muy agraciadas fisicamente, eran magníficas jugadoras $[\ldots]^{73}$

El ritmo de trabajo de una entrenadora era muy intenso y requería una entrega casi total, que en el caso particular de Alura Flores fue posible entre otros factores debido a la estricta disciplina de su religión bautista, inculcada desde la niñez. Esta entrega contrastaba con el rechazo masculino y lo hacia más injusto.

No tienen más ellos que uno, ni yo más que ellos. Simplemente la calidad del entrenamiento, la entrega que tú como entrenador le das, la categoría que siembras en el corazón del jugador. ${ }^{74}$

Alura Flores está consciente de que tuvo que hacer un esfuerzo especial como mujer para llegar a su nivel profesional:

es la corona más grande que tengo, porque para una mujer, que llegara a esa posición, no era fácil. ${ }^{75}$

Un poco diferente repasa Josefina Vicens sus años como secretaria de Acción Femenil de la CNC y del PNR de Calles, cargos que obtuvo después de ser secretaria en el Departamento Agrario. Co-

"Flores, p. 19.

72. Ibid.

73 Flores, p. 19.

74 Ibid.

${ }^{75}$ Flores, p. 21. 
rrian los años de los gobiernos de Lázaro Cárdenas, Manuel Avila Camacho y Miguel Alemán.

Con pocas excepciones, ella era la única mujer en los viajes, que formaban parte de sus actividades.

Yo debo decir -porque si no, seria yo injusta absoluta- que en estos viajes los compañeros de la CNC me trataban con gran respeto. Incluso en algunas ocasiones en que era una cosa difícil, con protección: "mira tú siéntate mejor allá, porque aquí está muy amontonado". ${ }^{76}$

\section{Los entonces lideres de la Campesina eran sus amigos:}

Era un ambiente muy fraternal. No habia envidias, ni discusiones, ni esto. Y cuando un compañero se presentaba para un puesto de elección, lo ayudábamos mucho, íbamos a su campaña y todo. Como mujer, jamás me senti discriminada ni limitada, probablemente porque se trataba de la gente de que se trataba. ${ }^{77}$

Es posible que realmente el azar hubiera reunido a un grupo de personajes extraordinarios y por encima de los prejuicios de su época. Pero también es posible que Josefina Vicens no invadiera el territorio masculino a un grado que provocara fricciones mayores. Se encargaba de cuestiones de organización de las mujeres campesinas, ámbito, que, al igual por cierto que la actividad de psicóloga de la juez Zúniga, podía considerarse propio de una mujer dentro de una división de trabajo por géneros. $Y$ "nunca se [le] ocurrió jugar para un puesto de elección", cuando la lucha electoral era y sigue siendo uno de los campos claves en el manejo del poder político. Es decir, estaba dentro del juego, pero no seguia de manera estricta sus reglas (masculinas) para ganar.

Sus actividades profesionales permitían a las tres entrevistadas entrar en contacto con algunas facetas de la realidad mexicana que distaban bastante de la relativa calma de su entorno clasemediero. La juez Zúñiga se acercaba a la vida de las clases subalternas urbanas, a problemas como desintegración familiar, delincuencia infantil y juvenil, alcoholismo, prostitución, etc. Alura Flores, como maestra de educación física, conocia el mundo indigena a través de su trabajo en las misiones culturales, creadas por José Vasconcelos. Josefina Vicens, finalmente, trataba en sus viajes como secretaria de Acción Femenil con la población rural y su lucha por un pedazo de tierra. Cada una juzga de manera diferente esta otra realidad, pero las tres comparten un sentimiento de satisfacción por haber cumplido con una responsabilidad social más allá de su vida particular.

Siempre me he sentido cuando menos muy aprovechada en el sentido de aprender, de sentir que se sirve de algo, sea poquito $[. . .]^{78}$

Nuestra principal función era ayudar y servir en lo que nosotros considerábamos útil y necesario para la recreación fundamentalmente $[. . .]^{79}$

7o Vicens, p. 32

Ibid.

78 Zúniga, p. 19.

${ }^{74}$ Flores, p. 23. 
Yo siento que he podido dar a la medida de mi capacidad, para lo que Dios me pudo haber puesto en este mundo. ${ }^{80}$

A partir de su trabajo con grupos indigenas y a pesar de sus juicios un tanto etnocéntricos, Alura Flores desarrollaba un profundo interés en el folclor, especialmente en los trajes de los diferentes grupos étnicos. Esta dedicación le permitiria después, en varios viajes, incluso al extranjero, "llevar el mensaje de [su] patria" al mundo."

Para Josefina Vicens, su labor en el sector público con los campesinos contrastaba en ocasiones conflictivamente con su vida privada:

Cuando tuve que ir con la Campesina a visitar muchisimas regiones, entonces sí fui muy feliz. Hacía yo comparaciones, una reunión en mi casa no tenia ninguna validez junto a una reunión con esa gente. Porque con una mesura, con un respeto, con una humildad al mismo tiempo, solicitaban cosas muy importantes como era su parcela, su título de propiedad, su crédito para poder cosechar y todo eso. Entonces me parecia un insulto el otro ambiente en el que estaba. ${ }^{82}$

Al igual que Guadalupe Zúniga y Alura Flores, está convencida de que tanto en lo personal como en cuanto a la institución en la que servia, se cumplian las responsabilidades:

La Campesina realmente trabajaba mucho con los campesinos [...] sí, trabajamos fiel y muy honradamente. Eran buenos, la verdad. ${ }^{83}$

Por encima de las críticas a aspectos concretos de la realidad mexicana, las tres entrevistadas se identificaron (y aún lo hacen) con el pais y sus instituciones. Pero solamente Josefina Vicens asume explícitamente un acercamiento a la actividad política:

Era una doble vida. Tantito estaba yo en líos políticos y tantito estaba yo en los cafés [...] Pero quería mucho a mis compañeros a unos y a otros. De los intelectuales, no podría yo decir que eran mis compañeros de lucha, del trabajo [...] los oía yo hablar y me quedaba asi. ${ }^{84}$

A pesar de considerarse personalmente a salvo de una discriminación masculina, Josefína Vicens sí fue sensible ante esta discriminación a nivel social y se comprometió en la lucha por el sufragio femenino:

Peleé muchísimo por el voto, eso sí. Con un grupo muy grande de mujeres: Adelina Zendejas, Aurora Reyes [...] Con Concha Michel empezamos a hacer proselitismo porque sí, a mí sí me indignaba muchísimo eso [...] Todavía no había la cosa de que hubiera mujeres en cargos públicos, ni en diputados, ni en todo eso, pero lo del voto era ignominioso. ${ }^{85}$

\footnotetext{
80 Flores, p. 30.

81 Flores, p. 25 y ss.

82 Vicens, p. 23.

83 Vicens, p. 26.

st Vicens, p. 37.

85 Vicens, p. 32.
} 
Guadalupe Zúñiga no menciona un interés especial en cuestiones políticas y Alura Flores, pensando en la militancia política tradicional, afirma:

No tuve propiamente interés en participar en política [...] Entonces yo no fui ese tipo de persona, pero no dejé siempre de pensar en toda la obra realizada por mis compañeras, porque yo vivi precisamente en el momento de esa lucha en la que la mujer estaba pasando por muchas vicisitudes a fin de lograr los derechos de igualdad con el hombre. ${ }^{86}$

De la complejidad y riqueza del material de las entrevistadas hemos tratado aqui solamente algunos aspectos. Las limitaciones propias de un artículo no permitieron profundizar más. Sin embargo, aun esta visión somera permite algunas consideraciones finales.

Al tratar de caracterizar las actitudes de nuestras entrevistadas ante la vida, surgen palabras como "ambivalencia", "ambigùedad", "transición" y binomios como "continuidad y cambio", "aceptación y resistencia", etcétera.

En realidad, estos conceptos no pueden sorprendernos, ya que sus vidas individuales están marcadas por una sociedad en transición y sujeta a cambios profundos. Pero los procesos históricos, a diferencia de los planteamientos teóricos, no avanzan a saltos o rupturas bruscas, sino que arrastran mucho del bagaje viejo al seguir nuevos caminos. En el caso de las mujeres y en especial el de nuestras entrevistadas, hay muchas evidencias para este fenómeno. A las mujeres por lo general, se las colocaba fuera de los procesos históricos y se las asociaba a una naturaleza estática e invariable. De esta manera se construyó la ficción de una feminidad atemporal. Cuando las mujeres concretas se salían de los espacios supuestamente ahistóricos y entraban a la historicidad, la ficción de lo eterno femenino se hacía cada vez más insostenible y cada vez más ancha la brecha entre una ideologia conservadora y las necesidades del desarrollo histórico concreto.

Durante la infancia, los conflictos para nuestras entrevistadas eran menos obvios, ya que la sociedad en general y la misma familia se mostraban relativamente permisivas y tolerantes con los ninoos y las niñas respecto a la imposición de normas diferenciadas por género. Esto explica por qué esta fase de la vida se califica como feliz y se recuerda por sus posibilidades de hacer travesuras e incluso ser "malas", es decir moverse con un mínimo de libertad.

Las limitaciones vienen con la adolescencia y pubertad, cuando aumentan las exigencias de la familia y de la sociedad. La edad conlleva más conflictos $\mathrm{y}$, al mismo tiempo, más conciencia de estos conflictos.

Pero este periodo se recuerda también con una conciencia del carácter excepcional de la propia vida individual, frente a las condiciones sociales generales. En esta conciencia, las posibilidades individuales, por ejemplo en la educación superior, son vistas como un privilegio pero también como una conquista de quienes se saben pioneras.

En la conciencia de su otredad, las tres entrevistadas muestran

${ }^{\text {sh }}$ Flores, p. 30. 
lo que podriamos llamar una identidad de mujeres. Pero no se trata de una identidad homogénea, sino compleja y hasta contradictoria. Además, es básicamente una identidad de mujer individual y no perteneciente a un colectivo. Pocas veces dicen: "nosotras, las mujeres..." y a menudo, "yo como mujer diferente de los varones, pero diferente también de las demás mujeres". Eso es cierto incluso para Alura Flores y Josefina Vicens que estaban interesadas o participaban en la lucha por el sufragio femenino.

El discurso de las tres sobre temas clave para una concepción tradicional de la mujer -familia, matrimonio, maternidad- no puede calificarse precisamente como heterodoxo; se mueve dentro de tópicos bastante usuales. La desviación de las normas se realizó en la práctica. Aquí con matices diferentes, Guadalupe Zúñiga, Alura Flores y Josefina Vicens optaron por una estrategia de evasión. Las dos primeras asumieron formalmente los papeles de esposa y madre, pero delegaron una buena parte de las consecuencias concretas a otras mujeres, sus madres y sus sirvientas. Josefina Vicens rompió en la primera oportunidad con el compromiso formal y rechazó para sí una maternidad que no le habría permitido llevar la vida que había escogido.

En las narraciones existen otros indicios de un rechazo de los estereotipos sobre el deber ser femenino. Guadalupe Zúñiga y Josefina Vicens se confiesan carentes de cualidades domésticas básicas como cocinar o tejer. Ello implica, desde luego, un menosprecio hacia estas actividades. Alura Flores, por otra parte, en su trabajo como entrenadora deportiva, se dedicaba a una profesión considerada como monopolio masculino. En la caracterización física de las alumnas lo importante para su maestra es la entrega al deporte, no la apariencia.

Es evidente, que sólo la posición de clase con su infraestructura correspondiente (sobre todo el servicio doméstico), ofrecia las condiciones para convertir este rechazo en un plan de vida alternativo.

En el caso de estas tres mujeres, conciliar las esferas privada y pública, no era posible aparentemente. Al decidir su incursión en el mundo masculino, tuvieron que renunciar prácticamente a la vida privada, a sus limitaciones, pero también a sus satisfacciones. La vida de trabajo sobredeterminaba cualquier otro aspecto de su existencia. Es notable, por ejemplo, que al preguntárseles por sus amistades, las respuestas se refieren casi siempre a contactos con compañeros de trabajo, centrados a su vez en problemas de la actividad profesional. Ello explica quizá por qué no recuerdan las fricciones entre "lo privado" y "lo público".

A diferencia del reconocimiento de la vida privada y del cuestionamiento de la separación en esferas (que domina hoy en dia en el feminismo), en corrientes alternativas de las ciencias sociales y en la vida diaria de algunas mujeres, durante la primera mitad del siglo, al parecer era necesario aceptar esta separación y los valores que implicaba, y adaptarse a ellos, lo cual exigía una buena porción de autonegación.

La estrategia de vida de tres mujeres, que hemos intentado trazar con base en sus narraciones personales, tienen elementos de enfrentamiento, sobre todo en el nivel familiar en la adolescencia y juventud, de adaptación y aceptación de la sociedad masculina 
en la edad adulta y de conservación de valores femeninos, a pesar de que muchos de éstos quedaron descartados para la propia vida personal.

Nuestras historias son historias no de cualquier ser humano, sino de seres humanos femeninos, lo que se percibe aun en la negación de lo femenino. Son historias particulares, sus protagonistas no se conocen y las contaron por separado. Pero, a pesar de ello, se conectan entre si y con un contexto social mayor; nos permiten esbozar a grandes rasgos esa "jaula flexible e invisible" en la cual se mueven. 